\title{
Characterisation of electrical energy storage technologies
}

\author{
Helder Lopes Ferreira ${ }^{\mathrm{a}, *}$, Raquel Garde ${ }^{\mathrm{b}}$, Gianluca Fulli ${ }^{\mathrm{c}}$, Wil Kling ${ }^{\mathrm{a}}$, Joao Pecas Lopes ${ }^{\mathrm{d}}$ \\ ${ }^{a}$ Electrical Engineering Department, Eindhoven University of Technology, Den Dolech 2, 5612 AZ, P.O. Box 513, CR 2.11 5600 MB Eindhoven, The Netherlands \\ ${ }^{\mathrm{b}}$ CENER-National Renewable Energy Centre, Ciudad de la Innovacion 7, 31621 Sarriguren (Navarra), Spain \\ ${ }^{\mathrm{c}}$ European Commission, DG Joint Research Centre, Institute for Energy and Transport, P.O. Box 2, 1755 ZG Petten, The Netherlands \\ ${ }^{\mathrm{d}}$ Electrical Engineering Department, University of Porto, Portugal
}

\section{A R T I C L E I N F O}

\section{Article history:}

Received 8 November 2012

Received in revised form

6 February 2013

Accepted 10 February 2013

Available online 25 March 2013

\section{Keywords:}

Energy storage systems

Renewable energy integration

Electricity systems evolution

\begin{abstract}
A B S T R A C T
In the current situation with the unprecedented deployment of clean technologies for electricity generation, it is natural to expect that storage will play an important role in electricity networks. This paper provides a qualitative methodology to select the appropriate technology or mix of technologies for different applications. The multiple comparisons according to different characteristics distinguish this paper from others about energy storage systems.

Firstly, the different technologies available for energy storage, as discussed in the literature, are described and compared. The characteristics of the technologies are explained, including their current availability. In order to gain a better perspective, availability is cross-compared with maturity level. Moreover, information such as ratings, energy density, durability and costs is provided in table and graphic format for a straightforward comparison. Additionally, the different electric grid applications of energy storage technologies are described and categorised. For each of the categories, we describe the available technologies, both mature and potential. Finally, methods for connecting storage technologies are discussed.
\end{abstract}

(c) 2013 Elsevier Ltd. All rights reserved.

\section{Introduction to the structure of the electricity sector}

The European electricity sector is getting ready for a challenging evolution, which will happen at several levels. By way of example, $95 \%$ of the increase in primary energy consumption between 2005 and 2030 in Europe will be supplied by renewable energy sources (RES). Moreover, the total electricity expected to be generated from renewables will more than double over this period. After 2030, the deployment of renewable energy sources in Europe is expected to accelerate, in order to offset the reduction of between 80 and $95 \%$ in greenhouse gas emissions by 2050, decided by the EU Member States (EU-27) [1]. Nevertheless, the deployment of RES in the EU27 is already increasing steadily as can be seen from Fig. 1. Similarly, around the world other countries are evaluating their potential of reaching challenging goals of RES deployment, especially after the Fukushima accident [2-5].

In this situation, electrical energy storage can play a pivotal role in the EU-27 grid, providing several services for the network in order to balance and smooth variations in both load and generation.

\footnotetext{
* Corresponding author. Tel.: +31 402475530; fax: +31 402450735.

E-mail addresses: h.m.lopes.ferreira@gmail.com, h.m.lopes.ferreira@tue.nl (H.L. Ferreira).
}

With the increased deployment of renewables, where storage can act as a buffer to offset the effects of the intermittency of some natural power sources such as wind and solar, this capability gains even more in importance [6-8]. Moreover, the energy storage technologies associated with renewable energy sources have the capacity to change the role of the latter from energy supplier to power producer [9]. Using data from a recent survey by the JRC [10], the proportional investment in storage systems in Europe is shown in Fig. 2. The actual figures are confidential.

However, market players are confronted with some questions, for example regarding the limited price difference for the final consumer between peak and valley hours or the lack of experience in the commercial deployment of some of the technologies. This applies even to technologies that seem, theoretically at least, to be cost-effective. In fact, an EU-27 regulatory framework, covering not only power supply, but also energy supply and ancillary services, would be advantageous for the deployment of storage technologies.

Actually, one of the reasons why large investments on storage are not attractive from the economic point of view is due to the insufficient remuneration of ancillary services such as balancing services and payments for reserves.

Independently of these considerations, the ability of storage technologies to act as a 'shock absorber' for the electricity infrastructure, thus enhancing its efficiency, reliability and security, is an 


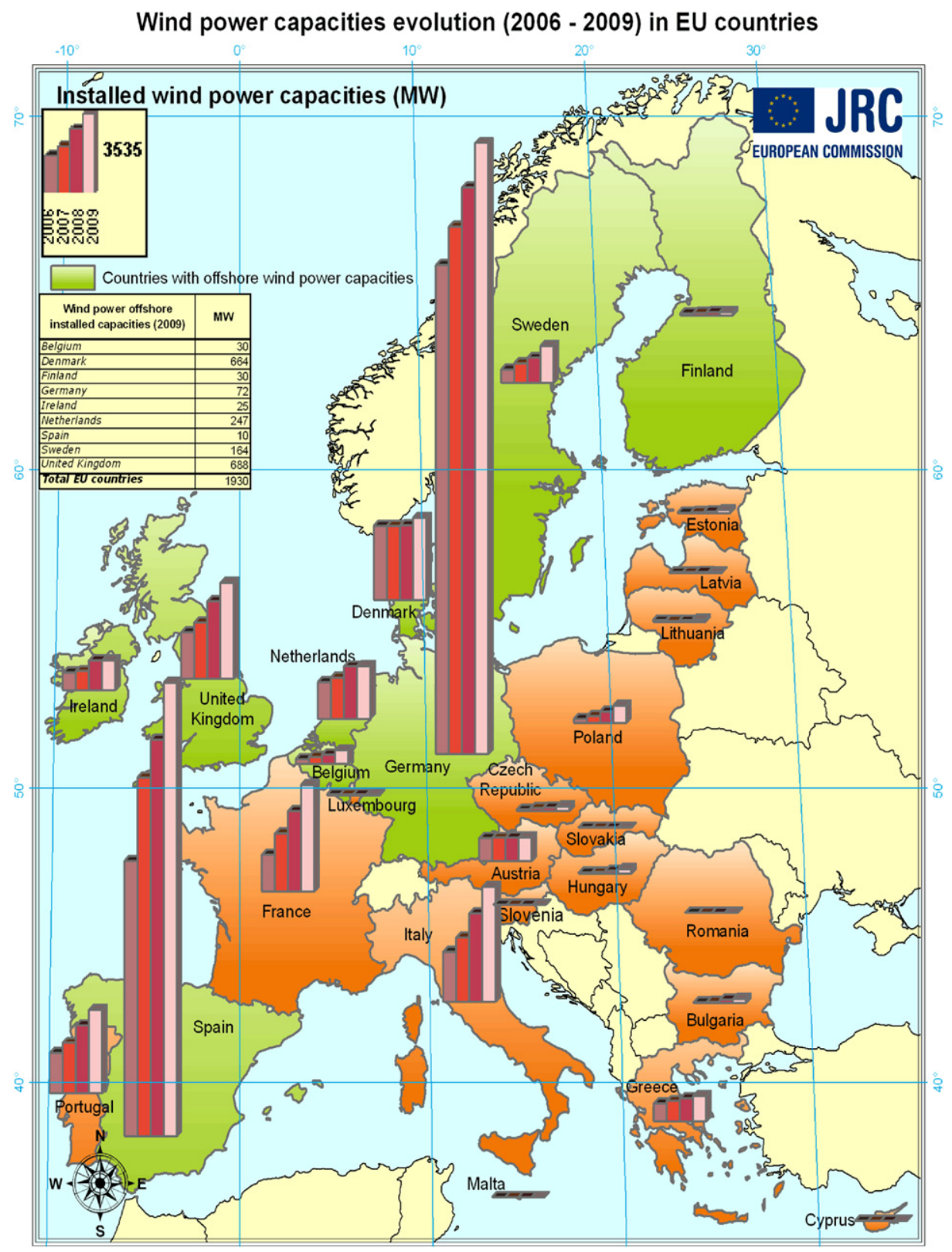

Fig. 1. Evolution of wind power capacities in the EU-27 countries.

important asset for the future electricity network: 'by maintaining even a relatively modest amount of reserves, storage facilities - big and small - will have a positive impact on the market' [11]. This positive impact can take the form of dampening the volatility of electricity market prices, increasing the efficiency of the market, fostering quantification of the value of ancillary services [12], and even improving security in the case of conflicts. In the retail energy sector, storage can reduce energy costs through peak shaving, while improving the quality of power, enhancing service reliability and avoiding spillage of renewable electricity. In countries with large variable renewable generation it happens that during valley hours, renewable generation can be spilled if no storage is used. The quantification of avoided $\mathrm{CO}_{2}$ emissions because of the use of storage for this purpose should be checked in order to value additionally storage investments.

Moreover, storage technologies have a high deployment potential particularly in markets with an increasing cost difference between peak and valley hours. Integrating storage to ensure a profitable utilisation factor is therefore an important issue [13].

In order to complement the data gathered from the literature on the different technologies, we carried out a survey of manufacturers. In this survey, we requested average values for full cycle efficiency, durability (time and cycling), power and energy rating. The information collected was then incorporated in Table 1.

\section{Technologies}

\subsection{Pumped hydroelectric energy storage (PHES)}

For this storage method, two water reservoirs at different heights are used. In charging mode, the water is pumped from the lower to the upper reservoir. In discharging mode, the water flows from the upper into the lower reservoir, driving the reversible turbines and producing electricity. This is the most common 
Current EU-27 investment in storage technologies

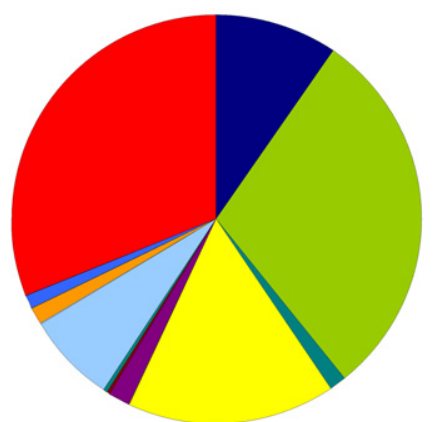

g.JRC

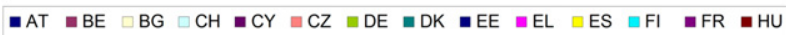

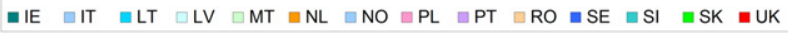

Fig. 2. Proportional investment of the EU-27 in storage technologies.

storage system in the electricity sector. It is traditionally dependent on natural conditions, usually making use of rivers or lakes. However, some innovative methods have emerged in recent years, such as use of the sea as the lower reservoir (Japan) or a proposal to use a surface reservoir as the upper reservoir and an underground reservoir, possibly below the other, as the lower reservoir.

It is a mature technology, widely deployed worldwide, with a high durability. The efficiency of older systems can be increased by retrofitting some of their components, in particular their turbines. Drawbacks are the location limitations, long lead times, environmental issues, and the high initial costs [14].

Dinorwig (UK) with $1800 \mathrm{MW}$ is the largest facility of this type in Europe, with a black start capability.

\subsection{Compressed air energy storage (CAES)}

When charging, a CAES device compresses air into reservoirs, which may be natural caves or artificial. When the cycle is inverted, electricity is produced by turbines. A conventional system has a limited efficiency due to the heat radiated to the atmosphere during compression. This effect is offset by using natural gas or another fuel in the discharging phase.

In an adiabatic system, the heat is stored in a special reservoir and reused to increase the discharge efficiency. This heat is stored in solid or liquid media [15]. In an isothermal system, almost no heat is radiated due to the use of a special device functioning simultaneously as a heat exchanger and a compressor [9].

Its advantages are durability and flexible size. The disadvantages are the initial capital costs, slow response, and limitations in terms of location. To overcome these drawbacks, the construction of storage tanks has been proposed, particularly for the deployment of small-scale CAES.

The conventional type of system has been deployed in a few installations worldwide and has been used for large-scale storage. The first system implemented worldwide was the one at Huntorf, in 1978 in Germany, with 220 MW. It is still functional and also has a black start capability. A project supported by the European Commission proposed Advanced Adiabatic CAES plants in different sizes for different applications [15].

\subsection{Chemical batteries}

A rechargeable battery comprises three major components: the positive electrode (cathode), the negative electrode (anode) and

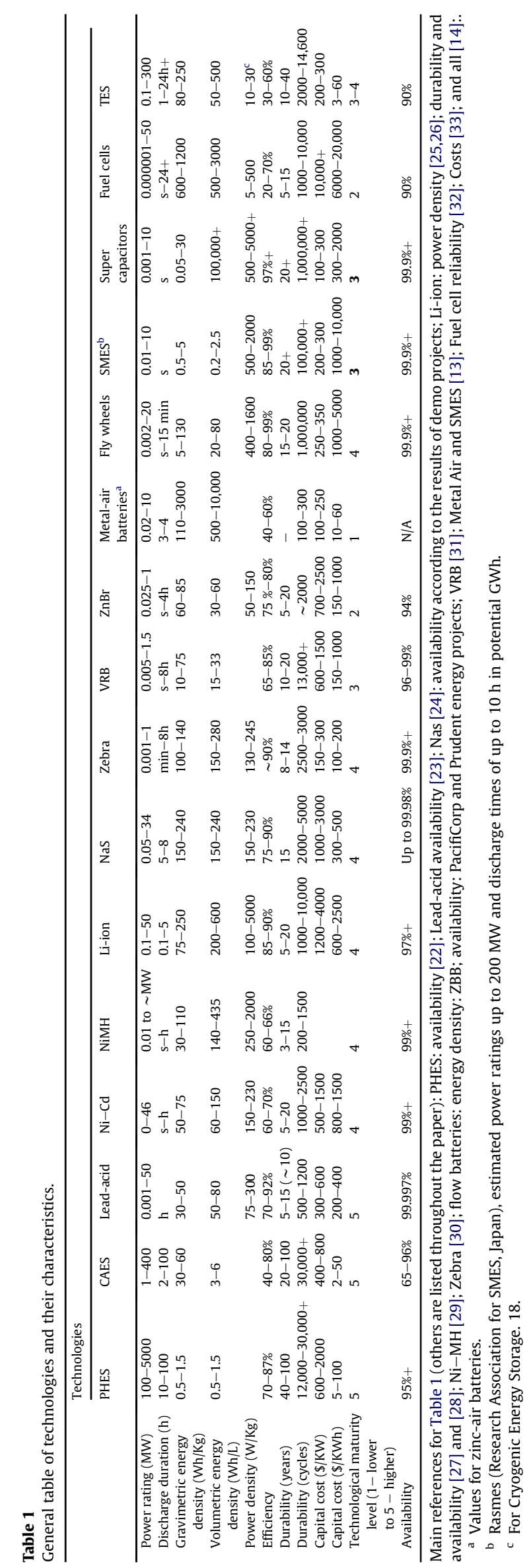


the electrolyte, solid or liquid, which together form an electrochemical cell. The electrodes are immersed in the electrolyte and the cell produces a voltage. Usually this voltage is less than $2 \mathrm{~V}$, but several electrochemical cells connected in series provide the output voltage. During discharge, redox (reduction-oxidation) reactions take place and the electric current flows in the external circuit from the cathode to the anode. As the reactions are reversible, the battery can be recharged by applying an external voltage across the electrodes. Depending on the electrodes and the electrolyte, there are many different batteries that can operate in different conditions for different applications. As the durability of the batteries depends on the depth of discharge, it is important to bear this in mind in evaluating these technologies.

\subsubsection{Lead-acid}

This is a mature technology, especially with the experience gathered from decades of use in the vehicle industry. The disadvantages are the poor low-temperature performance, low durability and environmental concerns due to the use of lead.

A typical facility is BEWAG in Berlin, with a capacity of $8.5 \mathrm{MWh} /$ $1 \mathrm{~h}$. In the survey, manufacturers stated that it was possible to store up to $80 \mathrm{MWh}$ in these devices.

\subsubsection{Nickel cadmium ( $\mathrm{Ni}-\mathrm{Cd})$}

A mature technology, initially deployed at appliance level, it offers advantages such as robustness to deep discharges, a long life cycle, temperature tolerance, and a higher energy density than lead-acid [16]. Drawbacks are the use of cadmium, a highly toxic material, the costs, the need for advanced monitoring during charge and discharge, due to the memory effect, and the periodic need to perform a complete cycle. It is seen by some authors [16] as a promising technology. In Europe, however, its use for consumer appliances has been banned by Directive 2006/66/EC. The technology has been deployed at the Golden Valley Electric Association, Alaska, providing $27 \mathrm{MW}$ for $15 \mathrm{~min}$ or $46 \mathrm{MW}$ for $5 \mathrm{~min}$ for VAR support, spinning reserve, frequency regulation, power system stabilisation, load following, load levelling and black start applications.

\subsubsection{Nickel-metal hydride (NiMH)}

A variant of NiCd, this technology has a higher energy density and is more environmentally friendly due to the use of non-toxic materials. The drawbacks include the high self-discharge of the basic version and the dependency on the limited supply of rare earth materials. It is used in consumer electronics. In rating terms, it is available up to the KW scale, being used in electric vehicles [16].

\subsubsection{Lithium ion (Li-ion)}

Highly deployed in the market for small appliances, these batteries have a very high efficiency and reliability, a good energy density and a slow self-discharge rate. However they are still expensive for medium- and large-scale power, even though they are being deployed more widely, which will probably lower the cost. Their energy capacity may reach $30 \mathrm{MWh}$.

\subsubsection{Sodium-sulphur (NaS)}

This is a high-temperature battery, with a working temperature in the region of $300{ }^{\circ} \mathrm{C}$. Its advantages include quick reversibility between charging and discharging, efficient operation, the ability to provide pulse power over six times its continuous power rating [9], low maintenance, long life, and good scale production potential. One drawback is that it needs to maintain a high operating temperature, which discharges it indirectly. It is an economic option for both power quality and peak shaving. Some authors state that this technology has corrosion problems that may impair its reliability [16].
In Europe, some systems have been installed in Germany. At present, the world's largest is installed in Japan with a rating of $34 \mathrm{MW}$ and $220 \mathrm{MWh}$

\subsubsection{Sodium nickel-chloride ( $\mathrm{Na}-\mathrm{Ni}-\mathrm{Cl}$ or zebra)}

Small and light, this technology possesses a fast response, robustness to full discharge and a very high energy density. Its drawbacks include its high cost and self-discharge. Some authors foresee a great potential for these devices in conjunction with intermittent renewable energy [17]. Until now, the technology has mostly been used in electric vehicles and submarines.

\subsection{Flow batteries}

Flow batteries are electrochemical devices which store energy in solutions (electrolytes) containing dissolved electroactive species. To release energy, a reversible electrochemical reaction between the two electrolytes takes place at the electrodes forming the electrochemical cells. Unlike conventional batteries, which contain the reactive compounds, redox flow batteries use electrolyte solutions stored in external tanks, so the capacity of the system is determined by the size of the electrolyte tanks, while the system power is determined by the size of the cell stacks, allowing independent scaling of power and energy capacities.

Flow batteries are highly flexible in terms of energy, as the energy is proportional to the amount of electrolyte utilised. They have a high efficiency, short response times when compared to other batteries, symmetrical charge and discharge, and quick cycle inversion. Also, they can be optimised for either real power (MW) or reactive power (MVAR). The drawbacks are the low power density, the toxicity of some materials used and insufficient deployment at commercial level. Nevertheless, vanadium redox (VRB) and zinc bromide ( $\mathrm{ZnBr}$ ) batteries are available on the market. Other subtypes exist, such as the vanadium bromide battery, the zinc cerium battery, or the polysulphide bromide (PSB) battery, but are at an earlier stage of development.

A PSB plant was to be built at Innogy's Little Barford Power Station, UK, with $15 \mathrm{MW} / 120 \mathrm{MWh}$. VRB systems are installed at several locations worldwide, including a $15 \mathrm{~kW} \times 8 \mathrm{~h}$ power system in the SYS Lab in Risø (DTU), Denmark, a $250 \mathrm{~kW} \times 8$ h system installed by PacifiCorp in Moab, Utah, for load levelling (peak shaving) and a $50 \mathrm{~kW} \times 4 \mathrm{~h}$ system operated by the National Renewable Energy Centre (CENER), Spain.

\subsection{Metal-air batteries}

Metal-air batteries use metal as a fuel to supply electricity. This technology is said to have a high potential in the coming years. However, it still needs development, particularly as regards the recharging stage. Some devices are unable to recharge and need material replacement. Their low efficiency and low power output are barriers still to be overcome. The most developed system is zinc-air, although some references are also found to lithium-air. Its biggest advantage is the environmental impact, as it uses non-toxic and recyclable materials. The technology is still at an early stage of development, with some characteristics still to be evaluated.

\subsection{Flywheels}

Flywheels take advantage of the possibility to store electricity as kinetic energy. When it charges, the flywheel accelerates. When it discharges, the kinetic energy is withdrawn.

There are two main types: low- and high-speed, also termed high-power and high energy, respectively. The first type is cheaper but has a short discharge time (some seconds to a few minutes). 
The second type can supply energy for more time (up to an hour) but is about 100 times more expensive.

The advantages of this technology are its apparent immunity to the number of cycles, the speed of charging and discharging, power rating and modularity. The drawbacks are the limited energy storage for the low-speed type and the cost of the high-speed type.

This technology has been successfully deployed in remote electric systems, allowing further penetration of renewable energy sources at such locations. This is the case with the Flores and Graciosa islands in Portugal [18].

\subsection{Superconducting magnetic energy storage (SMES)}

In SMES, the energy is stored in a magnetic field created by the flow of direct current in a superconducting coil. These coils do not degrade with usage or time, so durability and reliability depend only on the auxiliary equipment, such as power converters. The advantages of SMES are high efficiency, durability and reliability, short response times, no self-discharge and low maintenance. The disadvantages are the very high cost and the impact of the magnetic field. It may be used for short-duration energy storage, particularly in PQ (power quality) and small-sized applications. This technology is suitable for connection at distribution level or at an end-user site for high-quality power. It is deployed commercially [9].

Several installations have been deployed worldwide, particularly in the US. Europe also possesses some devices, for example at the Technical University of Munich. Some authors envisage, as a goal for this technology, the production of $100 \mathrm{MW}$ devices by 2050 with an efficiency of $99 \%$ [19].

\subsection{Super capacitors}

Energy is stored in the electric field produced between the two electrodes of the capacitor. Compared with normal capacitors, super capacitors make use of their particular structure to provide an outstanding capacitance. The main features are their exceptional efficiency, the performance at low temperatures, no need for maintenance, immunity to deep discharges, speed of response, and extreme durability. Drawbacks are the high cost, high self-discharge, and low energy density. The technology is comparatively young, but has been evolving at a remarkable pace and is regarded as an excellent solution for voltage regulation [9]. These systems are being increasingly used in Japan in voltage sag regulators [20].

\subsection{Hydrogen storage systems (with fuel cells)}

Hydrogen can be used as storage medium for electricity. First the energy is stored by producing hydrogen, substance which is then stored, and finally used to produce electricity. Hydrogen can be produced by extracting it from fossil fuels, by reacting steam with methane or by electrolysis. This last method is the one that allows electricity to be stored in a direct way. Moreover, it is the most promising as it is the most cost efficient and does not produce pollutants [17]

In terms of storage of the hydrogen itself it can be stored using one of the following three techniques: pressured vaporous hydrogen, cold liquid hydrogen, or hydrogen compound in chemical or physical structures. The first one is suitable for big installations, the second one for the transportation of big quantities or mobile applications and the third one for applications where portability and space are relevant [9]

Finally the hydrogen is supplied to a fuel cell which then uses it to produce electricity.
Several types of fuel cells exist, with different levels of efficiency and cost. Some types are quite sensitive to non-continuous cycles.

\subsection{Thermal energy storage (TES)}

Thermal energy storage involves storing electricity as heat, either at low or high temperatures. When needed, the stored heat is converted into electricity by heat engines.

In broad terms, two thermal storage processes can be used [21]. One is based on the heat capacity of the storage medium and the other on the phase change of the storage medium. Several materials may be used as the storage medium, including water, molten salt and lithium fluoride.

Some thermal storage systems use either ice or chilled water, accumulating during the night all or part of the freezing capacity needed for the day. The technology can be found in fossil or biomass thermal power plants, where it is seen as a way of increasing efficiency by storing thermal energy at lower demand moments and using it at peak or higher demand moments. Similar systems are used in some concentrating solar power plants, as a way of storing the energy for times when it is more needed and/or keeping production constant by minimising the impact of events such as passing clouds. A third possibility is using this technology to convert electricity into heat, storing it and then inverting the process when that energy is needed [9].

\section{Comparison of technologies}

Table 1 compares all the technologies described above. The 'maturity' row gives a qualitative assessment.

In future work, we intend to model the impact of energy storage systems on the reliability of distribution networks. We have therefore used this assessment to calculate theoretical availability indices for our simulations.

\subsection{General table}

The economic aspect is always important for the choice of any technology, so we summarise the information provided in Table 1 in Fig. 3:

We have devoted particular attention to the information on the availability of the different technologies. As the figures for the availability of a proven technology have a different level of certainty than those for an unproven technology, we have combined the information on availability with assessments of maturity in Fig. 4. These are qualitative assessments from 1 (lower) to 5 (higher) based on the available literature, in particular [34].

\section{Characteristics of storage technologies}

Several aspects need to be examined to evaluate and differentiate the storage technologies available in order to select the most suitable device for a desired application. There is no perfect technology for storage, which means that any solution has to take the best advantage of a given technology or find a good compromise in a synergy of technologies.

\subsection{Efficiency}

Like any appliances using energy, storage devices exhibit losses. To evaluate the efficiency of a storage device, the full cycle has to be taken into account: charging, keeping that charge and discharging. The different technologies used are important for evaluating efficiency. Some devices use chemical transformations, others are based on physical processes, and a few are able to store electricity 


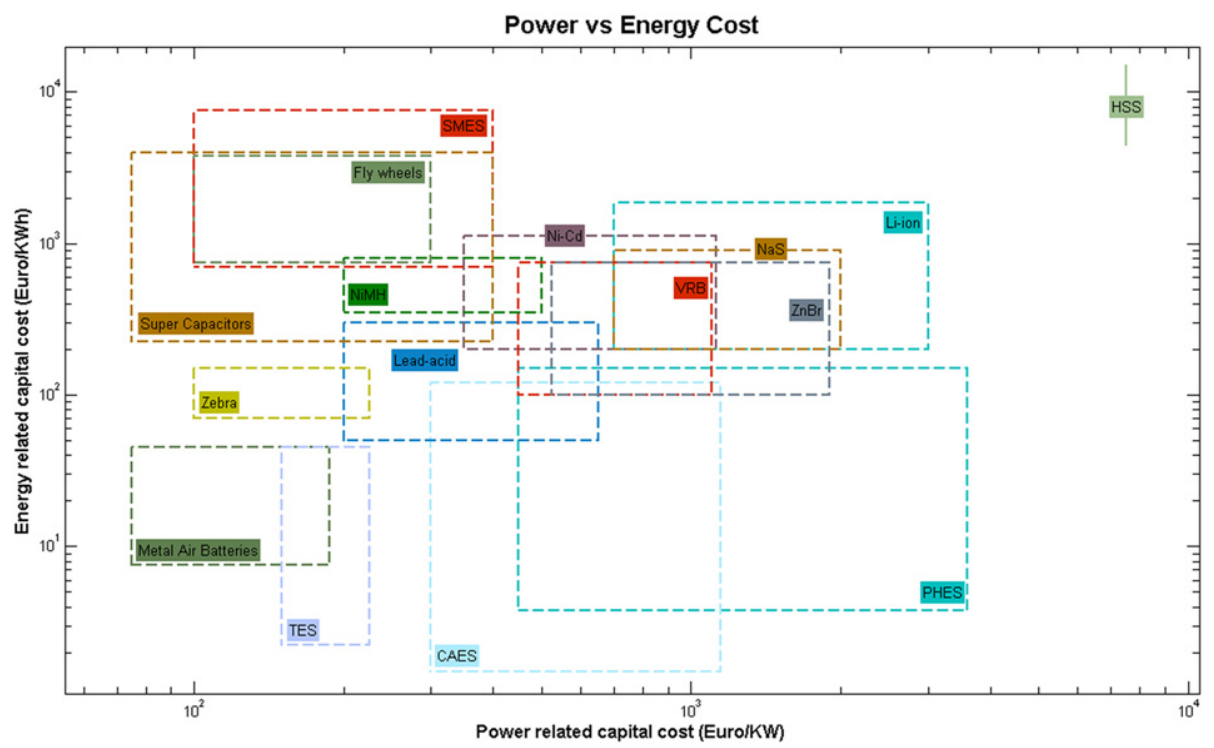

Fig. 3. Power vs. energy cost.

directly as electricity. In some cases, energy is needed for the device to keep the charge, while in others some energy is lost through time. Both situations are considered to involve a loss of efficiency.

\subsection{Durability}

Durability, or expected remaining life time, is an important factor for energy storage technologies. In some cases, it depends on the number of cycles, cycle depth or the no-return level of discharge. A cycle is defined as follows: 'A cycle is a full charge and discharge of the battery. If the battery constantly is charged and discharged $1 \%$, the number of such cycles that the battery is expected to be able to perform will be a 100 times as many as specified' [9]. Additionally, for some technologies, the temperature of the room where the device is placed and this temperature variation can be a relevant factor as well. Finally, ageing is always an important factor, and in some cases the only factor.

Fig. 5 shows the data in Table 1 in graphic form, to compare efficiency and durability using logarithmic scales.

\subsection{Energy and power density}

Energy and power density are relevant for evaluating the energy/power ratio of a technology and determining the size and weight of a given solution. These are important characteristics for applications with limited space and weight, such as transportation or mobile appliances, and for installation in urban areas where space is limited.

In Fig. 6, we have recalculated the data shown in this paper to create a Ragone plot, relating power and energy density along logarithmic scales.

\subsection{Reliability}

Reliability is the probability of a device performing its intended function over a specified period of time under stated conditions. It is usually evaluated using different, complementary indices. Two of the most common are Mean Time Between Failures (MTBF) and Mean Time To Recovery (MTTR). Availability is the proportion of

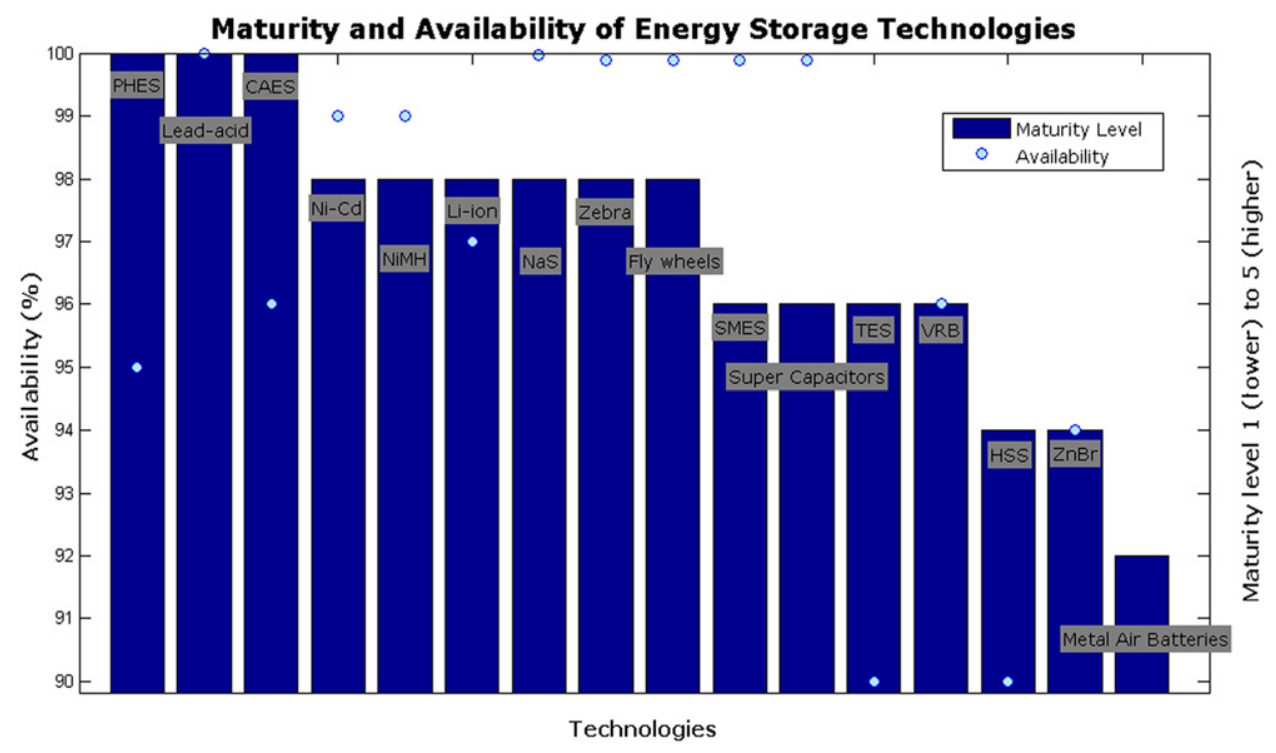

Fig. 4. Maturity and availability of energy storage technologies. Maturity level: 1 (lower) to 5 (higher). 


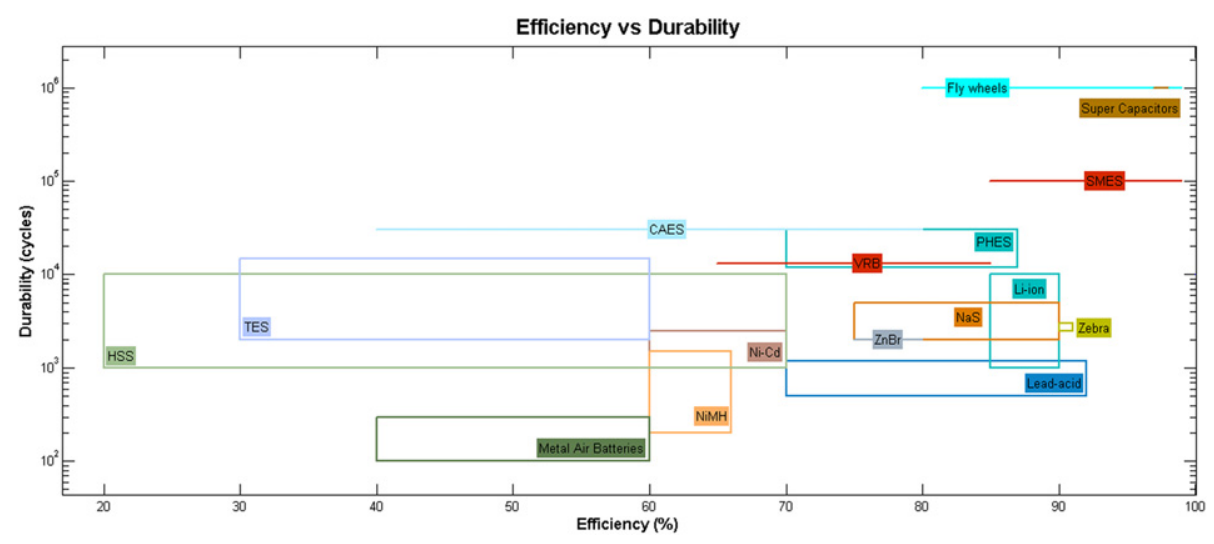

Fig. 5. Efficiency vs. durability.

time that a device or system is in a functioning condition. It is calculated using the following formula: availability $=\mathrm{MTBF} /$ (MTBF + MTTR) [35]. In the literature it is possible to find probabilities for both reliability and availability, the difference between the two being that the availability of a system takes into account planned outages, like regular maintenance.

To gain an idea of what these probabilities mean, an availability of $99.9 \%$ is equivalent to an MTTR of $1 \mathrm{~h}$ associated with an MTBF of 1000h (approximately 6 weeks of continuous work) and $99.99 \%$ is equivalent to an MTTR of $1 \mathrm{~h}$ for an MTBF of $10,000 \mathrm{~h}$.

The concept of availability or reliability can be difficult to evaluate in some cases, e.g. for batteries, In this case, for instance, there are many parameters that play a role in the availability and/or reliability of systems. The first is the application, which determines the number of cycles and state of charge (SoC) during charge/ discharge. These cycles must be very well controlled in order to protect the battery and ensure the expected life-time. Also, environmental aspects such as temperature and humidity influence the life time and cycling of systems.

\subsection{Response time}

Some applications require a quasi-instantaneous response time (milliseconds), others a few minutes. The response times of the available technologies likewise range from some milliseconds to some minutes.

\subsection{Storage capability: power vs energy}

In some of the literature, a distinction has been proposed between technologies providing power, delivering electricity for short periods, and those providing energy, delivering electricity for longer periods. Different applications exist for these two types of technologies. Some require only seconds or minutes of power, such as frequency control. Other applications may require hours, such as load levelling [9]. A combination of several applications may require the use of several devices to ensure the most cost-effective solution.

\section{Applications of storage technologies}

\subsection{Storage technologies have a wide range of applications, such as}

Load levelling - a strategy based on charging off-peak power and discharging the power at peak hours, in order to ensure a uniform load for generation, transmission and distribution systems, thus maximising the efficiency of the power system.

Peak shaving/valley filling - although the principle is the same for these two concepts, the focus is slightly different. Peak shaving concerns the minimisation of peak power and therefore the use of the more expensive power plants, while valley filling focuses on increasing the efficiency of the base plants by increasing the load at those moments.

Load following - providing a buffer, absorbing or injecting power to balance short-term variations between generation and load.

Spinning reserve - closely related to load following, this is described as the 'synchronised unused capacity that can be activated by the [system operator] to offset the differences between the scheduled load/production and the real load/production, controlling the frequency on the grid' [36].

Power quality - involving the mitigation of disturbances in the grid, such as flicker effects and voltage sags. Covering transient stability, voltage stability and power oscillation damping.

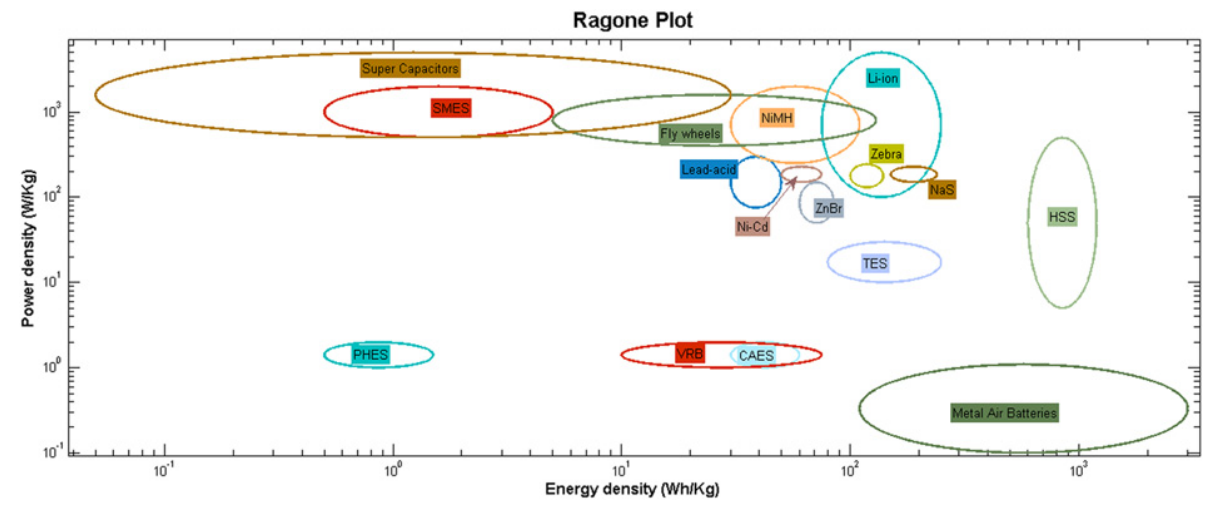

Fig. 6. Power vs. energy density (Ragone Plot). 
Table 2

Application categories and mature or potential future technologies.

\begin{tabular}{|c|c|c|c|}
\hline Category & Applications & $\begin{array}{l}\text { Mature } \\
\text { technologies }\end{array}$ & $\begin{array}{l}\text { Potential future } \\
\text { technologies }\end{array}$ \\
\hline \multirow{5}{*}{$\begin{array}{c}\text { Bulk energy } \\
\text { storage }\end{array}$} & Load levelling & Hydro & Flow batteries \\
\hline & Spinning reserve & CAES & Hydrogen storage \\
\hline & Peak shaving/Valley filling & TES & systems \\
\hline & Contingency service & $\mathrm{Ni}-\mathrm{Cd}$ & (using Fuel Cells) \\
\hline & Area control & Lead-Acid & \\
\hline \multirow{8}{*}{$\begin{array}{l}\text { Distributed } \\
\text { storage }\end{array}$} & Peak shaving/valley filling & CAES & Fuel cells \\
\hline & Investment deferral & Flywheels & Metal Air \\
\hline & Load following & Lead-acid & SMES \\
\hline & Demand side management & $\mathrm{NaS}$ & Flow batteries \\
\hline & Loss reduction & $\mathrm{Ni}-\mathrm{Cd}$ & Surface-CAES \\
\hline & Contingency service & TES & \\
\hline & Black start & & \\
\hline & Area control & & \\
\hline \multirow{4}{*}{$\begin{array}{l}\text { Power } \\
\text { quality }\end{array}$} & Power quality & Supercapacitors & Li-ion \\
\hline & Intermittency mitigation & Lead-acid & $\mathrm{NiMH}$ \\
\hline & End-use applications & $\mathrm{NaS}$ & SMES \\
\hline & Black start & Flywheels & Zebra \\
\hline
\end{tabular}

Investment deferral - for resolving congestion and deferring the upgrading of lines, cables and substations.

Intermittency mitigation - related to load following and spinning reserve, this is used in particular for intermittent renewables, such as wind or solar photovoltaic. Storage can minimise the impact of power variability on the network.

End-use applications - for levelling fluctuations, preventing voltage irregularities and providing frequency regulation for end-user equipment. Another use is as emergency backup, to maintain a very high level of reliability for the consumer if needed.

Demand-side management - through micro-storage located in end-user premises [11], users can minimise the cost of energy, or even achieve gains by buying energy off-peak and selling it on at peak hours.

Loss reduction - by decreasing network usage in the higher load periods and increasing it in the lower load periods, storage can increase the efficiency of the network and reduce energy transport costs [9].

Contingency service - providing a reserve if a power plant goes off-line [9].

Black start - enabling the power system to be restarted after a black out.

Area control - for preventing the unplanned transfer of power between neighbouring utilities.

\section{Analysis of the storage technologies and their integration in the electricity sector}

\subsection{Categorisation}

It is possible to categorise storage technologies by their applications, as is done by Ref. [36]. Some applications may go into more than one group [37]. We have therefore grouped the applications described above as follows:

$>$ Bulk energy storage, which includes applications such as load levelling, spinning reserve, energy transfer (peak shaving/ valley filling), contingency service, and area control;

$>$ Distributed storage, including peak shaving, investment deferral, load following, demand side management, loss reduction, contingency service, black start, and area control;

$\gg$ Power quality, including power quality, intermittency mitigation, end-use applications, and black start.

Another possible classification is that proposed by Ref. [9]:

$>$ Power quality, for short periods of time and rapid cycling energy needs, to maintain voltage and current within the required limits;

$>$ Bridging power, to ensure continuity of power supply over a period of minutes;

$>$ Energy management, concerning the supply of power to loads independently of the time of generation.

One has to bear in mind that not all technologies are suitable for all applications. This is due to limitations such as power output or storage capacity. Therefore, when categorising the technologies, we took into consideration their ratings. The results are set out in Table 2 .

Based on the information displayed in Table 1, the relationship between power and discharge duration can be evaluated corresponding to the energy of the device. The maximum energy range per technology is shown in the following Figs. 7-9, categorised according to Table 2 .

\subsection{Methods of connection}

In the literature, several methods of connecting energy storage devices to the network are described. The method used depends on the application. When the aim is to provide services such as peak shaving or frequency regulation, the device is connected to the

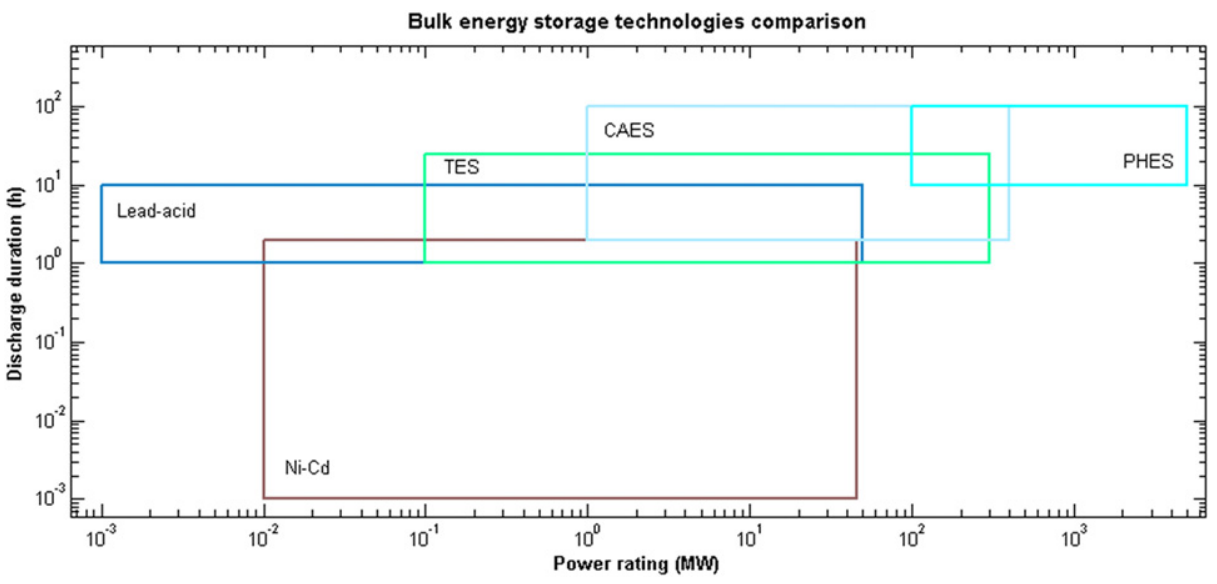

Fig. 7. Power vs. discharge duration for bulk energy storage technologies. 


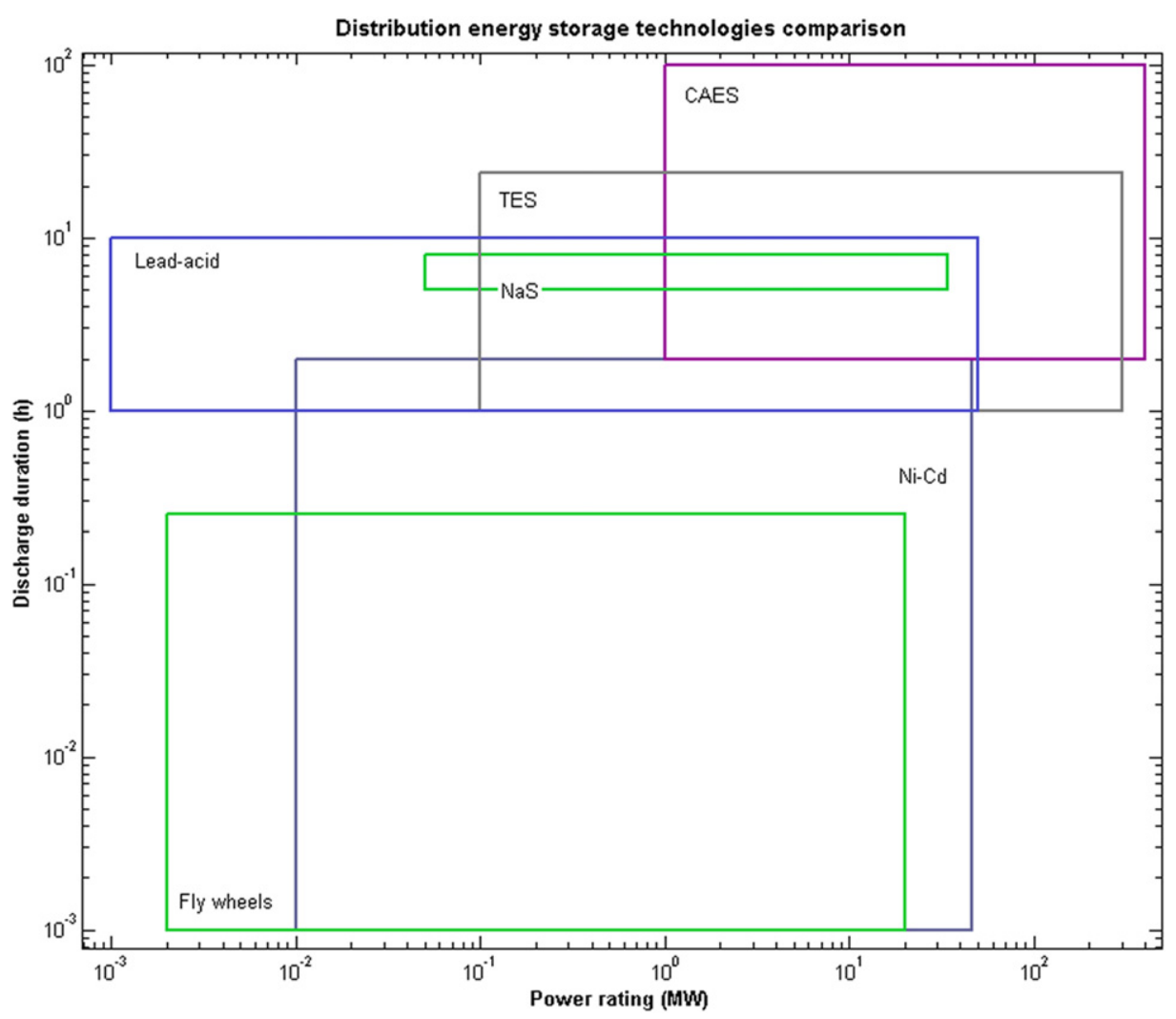

Fig. 8. Power vs. discharge duration for distribution energy storage technologies.

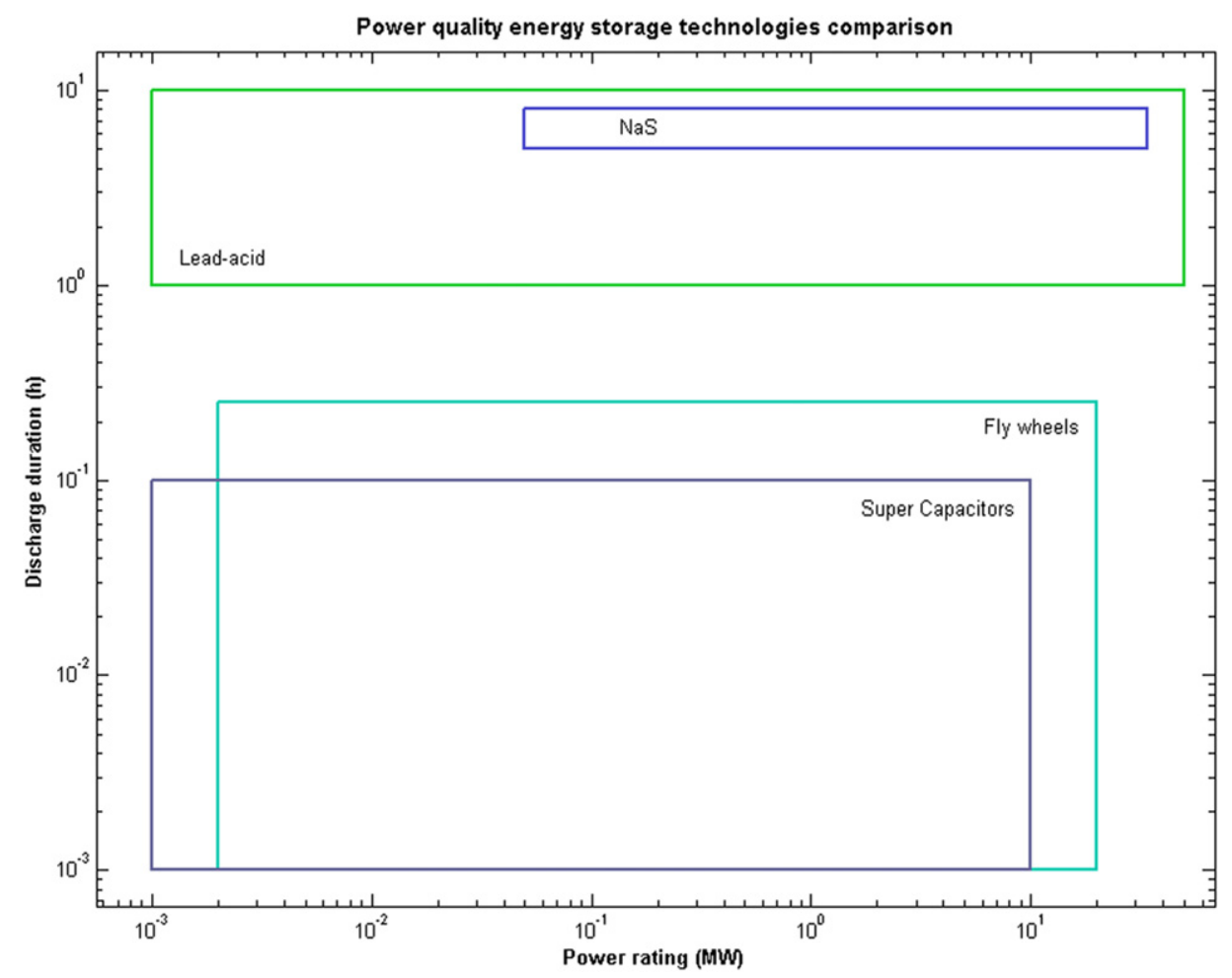

Fig. 9. Power vs. discharge duration for energy storage technologies suitable for power quality. 
network like a conventional generator. Another application, frequency regulation can be provided using this method or through $\mathrm{DC} / \mathrm{AC}$ interfaces that connect storage units to the grid. This is the case when voltage source inverter type units are used. These units are capable to emulate the behaviour of a synchronous machine together with its frequency regulation loops.

However, if the energy storage device is to provide uninterruptible power, it may be connected in three different ways: standby, line-interactive, or online, depending on the switching speed, quality of service, and rating.

Standby uses an integrated relay to switch between the network and the storage device, which takes at least a few milliseconds. However, it is satisfactory for many purposes.

Line-interactive mode can be seen as a variant of standby, but providing additional power quality services with attenuation of sags and spikes.

Online connection performs a double conversion: $A C / D C$ and then DC/AC, recreating the waveform. It ensures electrical isolation and can thus provide an 'electrical firewall' from the network for some installations. Moreover, it allows continuous supply with no switch delay. This type of connection is usually used in uninterruptible power supply systems in the MW range [9].

\section{Conclusions}

Electricity networks are facing an unprecedented evolution. In the coming decades, technologies will emerge to change the face of these traditionally technologically stable systems. The need to cater for a wide and growing range of renewable energy sources by 2020 , and by 2050 , can be seen as a major driver for this change. By 2050, GHG emissions in the EU-27 will be 80-95\% lower than in 1990. The huge RES expansion needed will be challenging for electricity networks, due to issues such as the variability of renewables. To cope with this variability, energy storage technologies are a natural answer.

Energy storage technologies are capable of providing several services to the network. Those services can be supplied for bulk or distributed storage or to ensure power quality, and concern not only power supply but also ancillary services. As listed above, they are: load levelling, peak shaving/valley filling, load following, spinning reserve, power quality, investment deferral, intermittency mitigation, end-use applications, demand side management, loss reduction, contingency service, black start, and area control. In order to provide these services, several methods of connection may be used. However, there is a problem with energy storage. This is that the benefits in all these applications have not yet been quantified. Therefore, their use is difficult to justify, taking into account the high capital costs and also the lack of support from the regulatory framework.

The technologies used for energy storage have different characteristics and are at different stages of maturity. In this paper, we have described and analysed sixteen of those technologies. We have compared the technologies with regard to power rating, discharge duration, energy density in terms of weight and volume, power density, efficiency, durability in terms of time and cycles, and availability.

Energy storage technologies exhibit a wide range of maturity levels. The most mature and most deployed technology worldwide is pumped hydroelectric energy storage, but technologies such as compressed energy storage and lead-acid batteries are proven as well. Others are already commercially available and also compete in the market, such as nickel-metal hydride batteries, sodium-sulphur batteries, lithium ion batteries, zebra batteries, flywheels, super magnetic energy storage, and super capacitors. Flow batteries and fuel cells are at a third level of technological maturity: they are under development and are seen as alternatives for the future market for energy storage.
Concerning future storage technologies, their integration to ensure a profitable utilisation factor is critical. Actually, one of the reasons why large investments on storage are not attractive from the economic point of view is due to the insufficient remuneration of ancillary services such as balancing services and payments for reserves. The analysis of these situations is quite interesting for the development of further research in this area. Therefore, it is in this topic that we intend to focus our future work.

\section{Disclaimer}

The views expressed are purely those of the writers and may not in any circumstances be regarded as stating an official position of the European Commission

\section{Acknowledgements}

Elena Corina Alecu, for creating the map for this paper.

All the companies that responded to the survey (ABB, Alstom, NGK, ZBB).

\section{References}

[1] European Commission. COM. 112 final, a roadmap for moving to a competitive low carbon economy in 2050; 2011.

[2] Mason IG, Page SC, Williamson AG. A 100\% renewable electricity generation system for New Zealand utilising hydro, wind, geothermal and biomass resources. Energy Policy August 2010;38(8). ISSN: 0301-4215:3973-84.. http://dx.doi.org/ 10.1016/j.enpol.2010.03.022. http://www.sciencedirect.com/science/article/pii/ S0301421510001850.

[3] Elliston B, Diesendorf M, MacGill I. Simulations of scenarios with $100 \%$ renewable electricity in the Australian National Electricity Market. Energy Policy June 2012;45. ISSN: 0301-4215:606-13.. http://dx.doi.org/10.1016/j.enpol.2012.03.011. http:// www.sciencedirect.com/science/article/pii/S0301421512002169.

[4] Ćosić B, Krajačić G, Duić N. A 100\% renewable energy system in the year 2050: the case of Macedonia. Energy December 2012;48(1). ISSN: 0360-5442:80-7.. http://dx.doi.org/10.1016/j.energy.2012.06.078. http://www.sciencedirect.com/ science/article/pii/S0360544212005300.

[5] Zhang Q Mclellan BC, Tezuka T, Ishihara KN. Economic and environmental analysis of power generation expansion in Japan considering Fukushima nuclear accident using a multi-objective optimization model. Energy August 2012;44(1). ISSN: 0360-5442:986-95.. $\quad$ http://dx.doi.org/10.1016/j.energy.2012.04.051. http://www.sciencedirect.com/science/article/pii/S0360544212003490.

[6] Lund H, Mathiesen BV. Energy system analysis of $100 \%$ renewable energy systems - the case of Denmark in years 2030 and 2050. Energy May 2009;34(5). ISSN: 0360-5442:524-31.. http://dx.doi.org/10.1016/j.energy.2008.04.003. http://www.sciencedirect.com/science/article/pii/S0360544208000959.

[7] Carton JG, Olabi AG. Wind/hydrogen hybrid systems: opportunity for Ireland's wind resource to provide consistent sustainable energy supply. Energy December 2010;35. ISSN: 0360-5442:4536-44.. http://dx.doi.org/10.1016/ j.energy.2010.09.010. http://www.sciencedirect.com/science/article/pii/S0360 544210004895.

[8] Østergaard PA. Comparing electricity, heat and biogas storages' impacts on renewable energy integration. Energy January 2012;37(1). ISSN: 0360-5442: 255-62.. http://dx.doi.org/10.1016/i.energy.2011.11.039. http://www.science direct.com/science/article/pii/S0360544211007705.

[9] CIGRE Working Group C6.15. Electric energy storage systems 2011.

[10] European Commission DG JRC and DG ENER. A view on Smart Grids projects in Europe: lessons learned and current developments 2011.

[11] Energy Storage Council. Energy storage - the missing link in the electricity value chain. An ESC White Paper; 2002.

[12] Drury E, Denholm P, Sioshansi R. The value of compressed air energy storage in energy and reserve markets. Energy August 2011;36(8). ISSN: 0360-5442: 4959-73.. http://dx.doi.org/10.1016/j.energy.2011.05.041. http://www.science direct.com/science/article/pii/S0360544211003665.

[13] Inage S-I. Prospects for large scale energy storage in decarbonised power grids. International Energy Agency; 2009. p. 19, 30.

[14] Chen H, Cong TN, Yang W, Tan C, Li Y, Ding Y. Progress in electrical energy storage system: a critical review. Prog Nat Sci 2009;19(3):291-312.

[15] Bullough C, Gatzen C, Jakiel C, Koller M, Nowi A, Zunft S. Advanced adiabatic compressed air energy storage for the integration of wind energy. European Wind Energy Conference, EWEC 2004, London UK; 2004.

[16] Pacific Northwest National Laboratory. Wide-area energy storage and management system to balance intermittent resources in the Bonneville power administration and California ISO control areas 2008 
[17] Connoly D, Leahy SM. An investigation into the energy storage technologies available, for the integration of alternative generation techniques. University of Limerick; 2007.

[18] Lopes Ferreira H. Evaluating the direct and indirect benefits, strengths and weaknesses of distributed energy storage in Europe. Energy Storage Forum 2011, Paris; 2011.

[19] Hall PJ, Bain EJ. Energy-storage technologies and electricity generation. Energy Policy 2008;36(12):4352-5.

[20] Sugimoto S, Hatano R, Nara s, Sakai Y, Okada K. Development of electric double-layer capacitor for energy storage and its application to the voltage sag compensator. In: CIGRE, editor. CIGRE Paris Session; 2008. p. D1-D103.

[21] Ter-Gazarian A. Energy storage for power systems. Peter Peregrinus Ltd; 1994.

[22] Codes E, Smith D, Tombs S, editors. Risk management and society. Kluwer Academic Publishers; 2000.

[23] Hale Jr PS, Arno RG. Survey of reliability information on lead acid batteries for commercial, industrial, and utility installations. In: Industrial and commercial power systems technical conference, 1999. Sparks, NV, USA: IEEE; 1999.

[24] Sandia National Laboratories. NAS ${ }^{\circledR}$ battery demonstration at American electric power. SANDIA Report. Printed March 2007.

[25] S. McCluer, Christin JF. Comparing data center batteries, flywheels and ultracapacitors.

[26] Vartanian C. A123 for wind integration, A123 systems. Europe, Barcelona, Spain: Energy Storage Forum; 2010.

[27] Lippert M. Entering the MW class: development of large scale lithium-ion energy storage systems. In: SAFT 5th International energy storage conference, Berlin; 2010
[28] Miller TJ. Lithium ion battery automotive applications and requirements. In: Conference lithium ion battery automotive applications and requirements, $\mathrm{p}$. 113-118.

[29] Zelinsky, Ovonic Ea. Storage-integrated PV systems using advanced NiMH battery technology. In: Fifth international renewable energy storage conference (IRES 2010). Berlin, Germany; 2010.

[30] Crugnola G, Sonick F. Simple sodium batteries: new applications for a proven technology energy storage forum Europe 2010, Barcelona, Spain; 2010.

[31] Li Liyu, Kim Soowhan, Wang Wei, Vijaayakumar M, Nie Zimin, Chen Baowei, et al. A stable vanadium redox-flow battery with high energy density for large-scale energy storage. Adv Energy Mater 2011.

[32] Nakken T, Strand LR, Frantzen E, Rohden R, Eide PO. The Utsira windhydrogen system - operational experience. European wind energy conference proceedings; 2006.

[33] Pedersen AH, Dong energy A/S. Electricity storage technologies for short term power system services at transmission level. Energy Storage Forum, Europe. Barcelona, Spain; 2010.

[34] European Commission. Technology map of the European strategic energy technology plan (SET-Plan) part - I: technology descriptions. JRC-SETIS Work Group; 2011.

[35] Barlow RE, Proschan F. Florida state University Tallahassee. Statistical theory of reliability and life testing: probability models 1975 .

[36] Keulenaer HD. Spinnning reserve - balancing the net. Minute lectures: Leonardo energy 2007.

[37] Schoenung SM, Hassenzahl WV. Long-vs. short-term energy storage technologies analysis - a life-cycle cost study. Albuquerque, USA: Laboratories SN; 2003. 